\title{
The Effects of Pilates on the Elderly: An Integrative Review
}

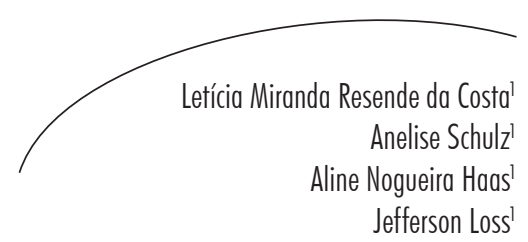

\section{Abstract}

Introduction: Pilates is considered a form of exercise that aims to improve flexibility, resistance, strength, balance and coordination. As a result, many elderly people have tried the method seeking to improve or maintain their health. Objective: The present study aimed to review the effects of Pilates on the elderly. Methods: An integrative review was carried out that studied elderly persons undergoing an intervention based on the Pilates method, combined or not with other techniques. The guiding question considered existing studies in literature that evaluated the effects of Pilates on the elderly. Searches of the MEDLINE (PubMed), Scopus and Physiotherapy Evidence Database (PEDro) electronic databases were conducted in May 2014. Results: Of a total of 445 studies found, 17 articles were included. Several variables were analyzed, with balance and the risk of falling described most frequently. Conclusions: The most studied variables were balance and the risk of falling and there was consensus among the studies regarding the improvement that Pilates caused in these variables. There was also agreement about increased flexibility, but controversy continues to surround the other effects reported in literature, or the data is isolated and therefore inconclusive. Among the studies found, most were experimental, and there were only two randomized controlled trials. The performance of more clinical trials featuring high quality methodological approaches addressing the theme is recommended, so that systematic reviews with meta-analysis may be performed, ensuring greater reliability of the results suggested in this study.

Keywords: Pilates, elderly, exercise, integrative review.

Universidade Federal do Rio Grande do Sul - UFRGS, Escola de Educação Física, Fisioterapia e Dança - ESEFID, Departamento de Educação Física. Rio Grande do Sul, Porto Alegre, Brasil.

Correspondence

Letícia Miranda Resende da Costa

Email: le_miranda7@yahoo.com.br 


\section{INTRODUCTION}

Life expectancy has undergone a global increase in recent years, resulting in the growth of the elderly population. ${ }^{1,2}$ Aging brings biological alterations ${ }^{3}$ and generates changes in psychological and social aspects, which compromise independence and quality of life. ${ }^{4}$

Exercise programs that involve strength and balance training are considered to be responsible for maintaining the functional capacity ${ }^{5}$ of the elderly, as well as being a preventive intervention to reduce the risk of falls in this population. ${ }^{6,7}$

One of the physical activities recommended for this group is the Pilates method, consisting of a system of physical exercises created by Joseph Pilates which involve body movements based on six principles: breathing, control, concentration, precision, fluidity and centralization, so integrating body and mind $^{8}$. The exercises are designed to promote improvement in posture, strength, endurance, flexibility and balance. ${ }^{9,10}$

Many elderly persons have tried the Pilates method in search of health and the maintenance of physical fitness and disease prevention, as well as adjuvant therapy. Literature contains a number of studies that seek to clarify the benefits of the Pilates method for this population. However, there is still no study that synthesizes these effects among the elderly population.

In seeking to systematize information about the effects of the Pilates method on this population, the aim of the present study was to perform an integrative review on the effects of the Pilates method on the elderly.

\section{METHOD}

The integrative literature review method was used, aiming to gather and summarize the scientific knowledge produced on the subject being studied. This allowed the search, evaluation and synthesis of available scientific evidence to facilitate the development of conclusions on the theme. ${ }^{11}$ Six stages were followed for the preparation of this study: establishing the research question and the objectives of the study; definition of the inclusion and exclusion criteria of the publications; literature search; analysis and categorization of studies; and presentation and discussion of results. ${ }^{11}$

The research question was: What are the effects of the Pilates method on elderly persons? The search was performed in May 2014 using the following electronic databases: MEDLINE (PubMed), Scopus and the Physiotherapy Evidence Database (PEDro). The year of publication was between 2004 and 2014, and the descriptor was a single term: Pilates. The search strategy used was to insert this term in the database and search. The inclusion criteria were: articles published in indexed journals of a population aged greater than or equal to 60 years undergoing intervention with the Pilates method, with or without other techniques. The exclusion criteria were: incomplete articles and articles in a language other than English, Portuguese and Spanish. The abstracts were read and evaluated by two independent evaluators and papers that met the established criteria were selected for the study and read in their entirety. An instrument for collecting information in order to answer the research question of this review was developed, composed of the following items: title, author, method, journal, year of publication, study objective and main results. The data was presented in tabular form. After reading the articles selected, an analysis and organization of the following themes was performed: Flexibility; Functional aspects; Risk of falls and balance; Body composition and cardiometabolic parameters; Body posture. Analysis, categorization and synthesis of the themes was carried out with the aim of achieving the best description and classification of the results. ${ }^{11}$

\section{RESULTS}

The search revealed 445 studies, of which 17 were considered eligible for data analysis (figure 1). 


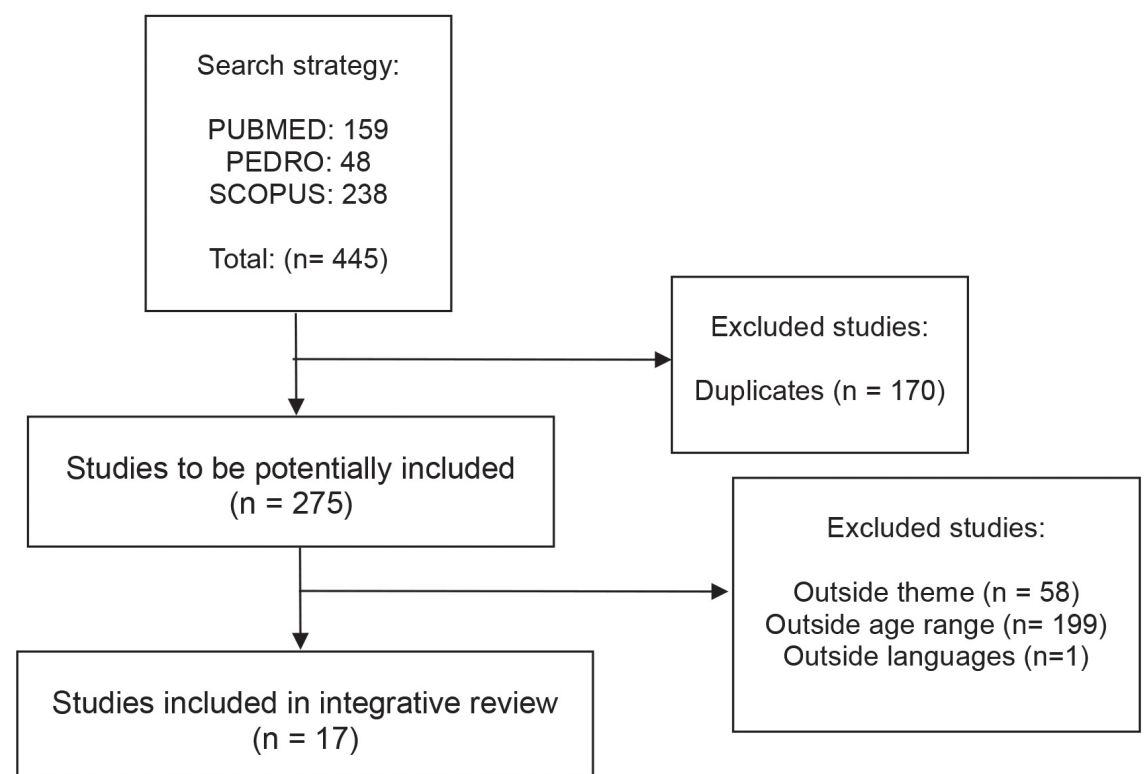

Figure 1. Review flowchart, 2014.

The variables of balance and risk of falls were the most researched, and all the studies found positive results. ${ }^{5,12-19}$ This was also the case for variables such as fat percentage, ${ }^{5,20,21}$ muscle strength, ${ }^{22}$ gait ${ }^{16,17}$ and quality of life. ${ }^{18}$ Other variables studied that presented positive results, albeit with only one study for each variable, were: motor coordination, ${ }^{3}$ personal autonomy ${ }^{18}$ spinal mobility, ${ }^{3}$ reaction time,${ }^{15}$ functional performance, ${ }^{12}$ systolic blood pressure ${ }^{21}$ and pain. ${ }^{16}$ Studies featuring the variables flexibility, ${ }^{15,16,20,22}$ strength $^{3,12,15}$ and posture ${ }^{23}$ presented controversial or inconclusive results or there was low adherence among hospitalized elderly persons in Pilates exercises ${ }^{24}$ (table 1). 
Table 1. Description of results of studies included in review, 2014-2015.

\begin{tabular}{|c|c|}
\hline Study & Results found \\
\hline Smith and Smith, $2005^{3}$ & $\begin{array}{l}\text { Strengthening of transversus abdominis, multifidus and pelvic floor muscles. } \\
\text { Improves balance, mobility of the spine and stability. }\end{array}$ \\
\hline $\begin{array}{l}\text { Ruiz-Montero, et al., } \\
2014^{5}\end{array}$ & $\begin{array}{l}\text { Pilates Group: reduction of fat percentage and fat mass. Increased lean body mass. } \\
\text { No changes in body weight and body mass index (BMI). Strong correlation between } \\
\text { fat mass and waist and hip ratio. Control group: no change. }\end{array}$ \\
\hline $\begin{array}{l}\text { Hyun, Hwangbo and } \\
\text { Lee, } 2014^{7}\end{array}$ & $\begin{array}{l}\text { Increased static and dynamic balance of both groups (Pilates and floor activities), } \\
\text { with the Pilates group achieving a greater reduction in oscillation. }\end{array}$ \\
\hline Granacher et al., $2013^{12}$ & Improved balance and functional performance and reduced risk of falls. \\
\hline $\begin{array}{l}\text { Bird, Hill and Fell, } \\
2012^{13}\end{array}$ & $\begin{array}{l}\text { Pilates Group: Improved static and dynamic balance. There was no improvement } \\
\text { in lower limb strength. Control group: no change. }\end{array}$ \\
\hline Bird and Fell, $2013^{14}$ & $\begin{array}{l}\text { Acute effects (five weeks): increased balance and lower limb strength. Long-term } \\
\text { effects ( } 12 \text { months): maintenance of static and dynamic balance. Lower limb strength } \\
\text { was maintained only in individuals who continued practicing Pilates. There was } \\
\text { an improvement in the risk of falls. }\end{array}$ \\
\hline Irez et al., $2011^{15}$ & $\begin{array}{l}\text { Pilates Group: Improvement in dynamic balance, flexibility, strength, reaction } \\
\text { time, and tendency to fall. Control group: no change. }\end{array}$ \\
\hline $\begin{array}{l}\text { Stivala and Hartley, } \\
2013^{16}\end{array}$ & $\begin{array}{l}\text { Increased balance, strength, range of motion and gait speed. There was a reduction } \\
\text { in pain and functional mobility, although there remained a risk of falls. }\end{array}$ \\
\hline $\begin{array}{l}\text { Newell, Shead and } \\
\text { Sloane, } 2012^{17}\end{array}$ & $\begin{array}{l}\text { Improvements in gait speed and step cycle and length. There was a reduced risk } \\
\text { of falls. }\end{array}$ \\
\hline Rodrigues et al., $2010^{18}$ & $\begin{array}{l}\text { Pilates Group: Improved personal autonomy, static balance and quality of life. } \\
\text { Control group: no change. }\end{array}$ \\
\hline Kaesler, et al., $2007^{19}$ & Improved static and dynamic balance. \\
\hline Fourie et al., 2013 $\mathrm{a}^{20}$ & $\begin{array}{l}\text { Pilates Group: improved shoulder flexion and hip flexibility, with no change in } \\
\text { shoulder and knee extension. Control group: Improved shoulder extension. }\end{array}$ \\
\hline Fourie et al., 2013c $\mathrm{c}^{21}$ & $\begin{array}{l}\text { Pilates Group: Decreased systolic blood pressure, diastolic blood pressure unchanged. } \\
\text { Total cholesterol and triglycerides unchanged. Both groups: increased glucose. } \\
\text { Control group: no further changes. }\end{array}$ \\
\hline $\begin{array}{l}\text { Plachy; Kovách; } \\
\text { Bognár, 2012²2 }\end{array}$ & $\begin{array}{l}\text { Pilates group and Pilates group associated with water exercises showed improvement } \\
\text { in physical strength, and flexibility and range of motion of the shoulder, hip, lumbar } \\
\text { spine, thoracolumbar and torso. Control group: no changes. }\end{array}$ \\
\hline $\begin{array}{l}\text { Kuo, Tully and Galea, } \\
2009^{23}\end{array}$ & $\begin{array}{l}\text { Immediate effect (after } 15 \text { weeks): decreased thoracic angle and increased lumbar } \\
\text { extension angle. Long-term effects (after } 20 \text { weeks): maintained alignments prior } \\
\text { to intervention. }\end{array}$ \\
\hline Mallery et al., $2010^{24}$ & $\begin{array}{l}\text { Pilates group compared to passive mobilization group had lower participation and } \\
\text { adherence. }\end{array}$ \\
\hline Fourie et al., 2013b ${ }^{25}$ & $\begin{array}{l}\text { Pilates Group: reduced fat mass and fat percentage and greater lean mass, no } \\
\text { changes in body mass and BMI. Control group: no change. }\end{array}$ \\
\hline
\end{tabular}


In terms of the type of study, the majority used experimental models, $5,7,13,15,18,20-22,24,25$ with only two randomized clinical trials. ${ }^{13,24}$ The other studies were of different types, with one literature review ${ }^{3}$, one systematic review ${ }^{12}$, one pilot study ${ }^{19}$, one longitudinal study, ${ }^{23}$ one case study ${ }^{16}$, one observational study ${ }^{17}$ and an observational prospective cohort study. ${ }^{14}$

\section{DISCUSSION}

Balance and the risk of falls were the most reported variables in literature. ${ }^{712-19}$ This fact can be justified by the balance deficit inherent to aging, which represents a major disabling factor among this population, interfering with functionality and quality of life. The topics described below were stipulated in order to facilitate understanding of the results with respect to all the variables described in the studies analyzed.

\section{Flexibility}

Flexibility is directly linked to the independence of elderly persons, as it is an extremely important component in movement. ${ }^{20}$ All the studies contained in this review that evaluated this variable were in agreement regarding the improvement of flexibility after a Pilates intervention. Fourie et al. ${ }^{20}$ evaluated 50 sedentary elderly women divided into two groups, one which underwent Pilates exercises three times a week and a group that went without exercise for eight weeks. The authors identified improvement in the flexibility of the shoulder and hip flexors, although there was no difference in the extensors of the same joints. The decrease in body fat percentage, which possibly generates a mechanical barrier to movement, was described as one of the factors that contributed to this result. However, the control group presented improved shoulder extension.

Plachy, Kovach e Bognár ${ }^{22}$ investigated 42 elderly persons, randomly divided into three groups. The first group performed Pilates three times a week, the second underwent Pilates once a week, combined with water exercise twice a week, while the third did not perform physical exercise during the study period of six months. The groups who performed Pilates presented improved flexibility in comparison with the control group. The second group had significant improvement in shoulder, hip, lumbar spine, thoracolumbar and trunk flexibility. The control group remained unchanged. Corroborating these results, Irez et al., ${ }^{15}$ who evaluated 60 elderly persons over 12 weeks, divided into an intervention group which performed pilates three times a week and a control group, identified improvements in flexibility.

\section{Functional aspects}

Aging brings a decline in muscle mass and subsequently strength. Training involving muscle resistance and strength exercises is very important for the elderly when preventing the loss of muscle and bone mass due to aging. ${ }^{13}$ The term functional aspects is extremely broad and includes many variables, such as strength, range of motion, mobility and stamina. Few studies assessed these valences. A study by Plachy, Kovach and Bognár, ${ }^{22}$ addressed range of motion and physical resistance. The results showed an improvement in these aspects in both groups that performed an exercise routine, but elderly individuals who practiced only the Pilates Method also demonstrated an improvement in muscle control. The authors state that this improvement may be related to the strengthening of the center of the body, which brings stability and safety when performing movements.

In order to improve functional aspects related to loss of strength and muscle mass, Mallery et al. ${ }^{24}$ conducted a study with 39 hospitalized patients, which included an evaluation of participation in and adherence to the training. Patients were divided into a control group, which performed passive movements with the aid of a physiotherapist, and an experimental group, who performed the Pilates exercises. Adhesion was higher in the passive movements group. According to the authors, this difference can be explained by the greater intensity of the Pilates method and also by the intervention period, which was more than three times longer in the Pilates group. 
Regarding lower limb strength, Bird, Hill and Fell ${ }^{13}$ evaluated this aspect and found no difference between groups that practiced and did not practice the method. A year later, however, the same authors found increased strength in another study ${ }^{14}$ with a similar design, corroborating the results of Riz et al., ${ }^{15}$ who achieved the same findings with a more expressive sample and a longer follow-up.

There were two systematic reviews with functional aspects among their objectives. In the review by Smith and Smith, ${ }^{3}$ the authors found evidence of the strengthening of the transversus abdominis, multifidus and pelvic floor muscles, improving body stability and mobility of the spine. Granacher, Gollhfer and Hortobágyi ${ }^{12}$ meanwhile, investigated the possible correlation between functional aspects and falls, with the results suggesting that increased body center strength is related to a reduced risk of falls.

\section{Risk of falls and Balance}

The risk of falls can be assessed in different ways, with static balance, dynamic balance and strength of the lower limbs the most commonly used parameters in the selected studies. Granacher, Gollhfer and Hortobágyi, ${ }^{12}$ in the systematic review described above, concluded that strengthening the center of the body through intervention with Pilates can contribute to the efficiency of the extremities of the body, improving balance among the elderly. In the study of Bird, Hill and Fell, ${ }^{13} 27$ elderly persons were divided into two groups, one that performed Pilates twice a week for five weeks and a group without physical activity during this period. The results showed little improvement in static and dynamic balance in Pilates group, with no increase in lower limb strength. The study of Bird and Fell, ${ }^{14}$ however, which was also developed over five weeks and evaluated 30 elderly persons, identified an improvement in lower limb strength, as well as increased balance and a decrease in the risk of falls. This study also performed a followup evaluation after 12 months of intervention and found that the elderly persons retained better static and dynamic balance values and a reduced risk of falls, regardless of whether they continued the practice of Pilates or not. However, elderly persons who continued Pilates exercises obtained further increases in static and dynamic balance and still maintained the strength gains. The study by Kaesler et al. ${ }^{19}$ corroborated these results. This study evaluated seven people for eight weeks, twice per week. The authors concluded that Pilates training can improve static and dynamic balance, reducing the risk of falls.

A case study by Stivala and Hartley ${ }^{16}$ evaluated the use of the Pilates method in the rehabilitation of an elderly women aged 84 years after hip surgery due to a fall. The results showed that the patient achieved improvements in balance, range of motion and gait speed, but still had a high risk of falls.

Flexibility, reaction time, dynamic balance, strength of lower limbs and propensity to fall were studied by Irez et al. ${ }^{15}$ The authors analyzed 60 elderly persons, divided into an intervention group that performed Pilates three times a week for 12 weeks and a control group. There was improvement in all the parameters and a reduced risk of falls.

Newell, Shead and Sloane ${ }^{17}$ analyzed gait parameters, balance and risk of falls in nine elderly women who practiced Pilates once a week for eight weeks, concomitantly with walking on a treadmill. The results showed improvement in gait speed and cycle and step length, with a subsequent reduction in risk of falls. However, these results should be analyzed with caution, as the intervention did not only involve Pilates.

When comparing the effects of Pilates and an unstable platform in 40 elderly persons, Hyum, Hwangbo and Lee concluded that both types of training brought benefits in balance, but the Pilates group achieved a greater decrease in oscillation. Rodrigues $e t a l,{ }^{18}$ meanwhile, assessed the effects of Pilates on static equilibrium, personal autonomy and quality of life. The authors concluded that there was an improvement in static balance and level of personal autonomy in the Pilates group. Corroborating these results, Kaesler et al. ${ }^{19}$ also found improvements in static and dynamic balance 
and a reduced risk of falls among elderly persons who practiced Pilates.

\section{Body composition and cardiometabolic parameters}

Fourie et al. ${ }^{25}$ evaluated 50 elderly persons divided into a Pilates group, which practiced three times a week for eight weeks, and a control group. The results were a decrease in the percentage of fat and fat mass and an increase in lean mass in those practicing Pilates. There were no changes in body weight and body mass index. The control group showed no changes. Other variables were evaluated by Fourie et al. ${ }^{21}$ such as blood pressure, fasting glucose, cholesterol and triglycerides. The Pilates group presented a reduction in systolic blood pressure, but no change in diastolic blood pressure. There were no changes in cholesterol and triglycerides. Both groups had increased glucose. This fact may be explained by the fact that the post-intervention assessments were carried out in winter, which is associated with a nutritional increase. However, the authors suggest that Pilates is not a substitute for forms of aerobic exercise when the goal is solely to improve cardiometabolic risk parameters.

The study by Ruiz-Montero et al. ${ }^{5}$ involved 303 elderly persons divided into an intervention group which performed Pilates combined with musicbased aerobics exercises, twice a week for 24 weeks, and a control group that did not perform physical activity. The intervention group presented reduced fat mass and fat percentage and an increase in lean mass, but there were no changes in body weight or body mass index. Again the results need to be analyzed with caution, as Pilates was combined with another type of physical exercise.

\section{REFERENCES}

1. Frontera WR, Bigard X. The benefits of strength training in the elderl. Sci Sports 2002;17:109-16.

2. Orfila F, Ferrer M, Lamarca R, Tebe C, DomingoSalvanY A, Alonso J. Gender differences in healthrelated quality of life among the elderly: the role of objective functional capacity and chronic conditions. Soc Sci Med 2006;63(9):2367-80.
Body posture

Only one item assessed body posture among the elderly. Kuo, Tully and Galea ${ }^{23}$ evaluated 34 elderly persons who performed Pilates for ten weeks. Postural analysis was performed by measuring the angles of the spine on the sagittal plane at three moments: before the experiment, fifteen weeks after the start of the intervention and after twenty weeks. After fifteen weeks, there was a decrease in the thoracic angle and an increase in the lumbar extension angle, while after 20 weeks there was no change from baseline.

Limitations of the present study included the fact that the methodological quality of the articles was not evaluated; the diversity of the research designs and intervention protocols, making proper comparison between the studies difficult; and the fact that the exclusion criteria rejected studies for which complete versions were not found, thus generating a significant publication bias.

\section{CONCLUSION}

We can infer that the positive effects of the Pilates method, namely improved balance and a reduced risk of falls, were agreed upon by the studies. While there was also a consensus among researchers regarding improved flexibility, there was controversy regarding the other effects reported in literature, with isolated, and thus inconclusive, data presented.

It is suggested that clinical trials are conducted, ensuring greater reliability of the effects of Pilates, allowing the concatenation of the results through future systematic reviews with meta-analysis.
3. Smith KAC, Smith EB. Integrating Pilates-based core strengthening into older adult fitness programs: implications for practice. Top Geriatr Rehabil 2005;21(1):57-67.

4. Mayer F, Scharhag-Rosenberger F, Carlsohn A, Cassel M, Müller S, Scharhag J. The Intensity and effects of strength training in the elderly. Dtsch Ärztebl Int 2011;108(21):359-64. 
5. Ruiz-Montero PJ, Castillo-Rodrigues A, Mikakacki M, Nebojsa C, Korovljev D. 24-weeks Pilates-aerobic and educative training to improve body fat mass in elderly Serbian women. Clin Interv Aging 2014;31(9):243-8.

6. Clemson L, Singh MAF, Bundy A, Cumming RG, Manollaras K, O'Loughlin P, et al. Integration of balance and strength training into daily life activity to reduce rate of falls in older people (the LiFE study): randomised parallel trial. BMJ 2012;345:4547.

7. Hyun J, Hwangbo K, Lee CW. The effects of Pilates mat exercise on the balance ability of elderly females. J Phys Ther Sci 2014;26(2):291-3.

8. Anderson BD, Spector A. Introduction to PilatesBased Rehabilitation. Balanced Body 2005:1-8.

9. Kloubec J. Pilates: how does it work and who needs it? Muscles Ligaments Tendons J 2011;1(2):61-6.

10. Cruz-Ferreira A, Fernandes J, Laranjo L, Bernardo LM, Silva A. A systematic review of the effects of Pilates method of exercise in healthy people. Arch Phys Med Rehabil 2011 92:2071-81.

11. Mendes KDD, Silveira RCCP, Galvão CM. Revisão integrativa: método de pesquisa para a incorporação de evidências na saúde e na enfermagem. Texto \& contexto enferm 2008;17(4):758-64.

12. Granacher U, Gollhofer A, Hortobágyi T, Kressig RW, Muehlbauer T. The importance of trunk muscle strength for balance, functional performance, and fall prevention in seniors: a systematic review. Sports Med 2013;43(7):627-41.

13. Bird ML, Hill KD, Fell JW. A randomized controlled study investigating static and dynamic balance in older adults after training with Pilates. Arch Phys Med Rehabil 2012;93(1):43-9.

14. Bird ML, Fell J. Pilates Exercise has Positive Long Term Effects on the Aged-Related Decline in Balance and Strength in Older, Community Dwelling Men and Women. J Aging Phys Act. Epub ahead of print 2013.

15. Irez GB, Ozdemir RA, Evin R, Irez SG, Korkusuz F. Integrating Pilates exercise into an exercise program for $65+$ year-old women to reduce falls. J Sports Sci Med 2011;10(1):105-11.
16. Stivala A, Hartley G. The Effects of a Pilates-Based Exercise Rehabilitation Program on Functional Outcome and Fall Risk Reduction in an Aging Adult Status-Post Traumatic Hip Fracture due to Fall. J Geriatr Phys Ther. Epub ahead of print 2013.

17. Newell D, Shead V, Sloane L. Changes in gait and balance parameters in elderly subjects attending an 8-week supervised Pilates programme. J Bodyw Mov Ther 2012;16(4):549-54.

18. Rodrigues SBG, Cader AS, Torres BNV, Oliveira EM, Dantas MEH. Pilates method in personal autonomy, static balance and quality of life of elderly females. J Bodyw Mov Ther 2010;14(2):195-202.

19. Kaesler DSA, Mellifont RBB, Kelly PSC, Taaffe DRD. A novel balance exercise program for postural stability in older adults: a pilot study. J Bodyw Mov Ther 2007;11(1):37-43.

20. Fourie M, Gildenhuys GM, Shaw I, Shaw BS, Toriola AL, Goon DT. Effects of a mat Pilates program on flexibility in elderly women. Med Sport 2013;66(4):545-53.

21. Fourie M, Gildenhuys GM, Shaw I, Shaw BS, Toriola AL, Goon DT. Effects of a mat Pilates program on cardiometabolic parameters in elderly women. Pak J Med Sci 2013;29(2):500-4.

22. Plachy JA, Kovách MA, Bognár JB. Improving flexibility and endurance of elderly women through a six-month training programme. Hum Mov 2012;13(1):22-7.

23. Kuo YL, Tully EA, Galea MP. Sagittal spinal posture after Pilates-based exercise in healthy older adults. Spine 2009;34(10):1046-51.

24. Mallery LH, Macdonald EA, Hubley-Kozey CL, Earl ME, Rockwood K, MACKNIGHT C. The feasibility of performing resistance exercise with acutely ill hospitalized older adults. BMC Geriatr 2003;3(3):1-8.

25. Fourie M, Gildenhuys GM, Shaw I, Shaw BS, Toriola AL, Goon DT. Effects of a mat Pilates programme on body composition in elderly women. West Indian Med J 2013;62(6):524-8. 